\title{
A Study on the Bond Behavior of Corroded Reinforced Concrete Containing Recycled Aggregates
}

\author{
Haifeng Yang, ${ }^{1,2}$ Zhiheng Deng, ${ }^{1,2}$ Yinghong Qin, ${ }^{1,2}$ and Liangsheng $\mathrm{Lv}^{1,2}$ \\ ${ }^{1}$ College of Civil Engineering and Architecture, Guangxi University, 100 University Road, Nanning, Guangxi 530004, China \\ ${ }^{2}$ Key Laboratory of Disaster Prevention and Engineering Safety of Guangxi, Nanning 530004, China \\ Correspondence should be addressed to Haifeng Yang; yhfgxu@aliyun.com
}

Received 17 April 2015; Accepted 31 May 2015

Academic Editor: Robert Cerný

Copyright (c) 2015 Haifeng Yang et al. This is an open access article distributed under the Creative Commons Attribution License, which permits unrestricted use, distribution, and reproduction in any medium, provided the original work is properly cited.

\begin{abstract}
This paper investigated bond-slip characteristics of chloride-induced corroded reinforced concrete incorporating different levels of recycled concrete aggregates (RCA). Pullout tests were adopted to evaluate the bonding and debonding behaviors of the embedded rebar experiencing different corrosion levels. Both high- and low-strength concrete were considered. Bond-slip curves were recorded to determine the influences of rebar corrosion levels and RCA replacements on the bond strength and debonding energy of the specimens. Test results indicate that increasing rebar corrosion level gradually weakens the antisliding ability of reinforced recycled aggregate concrete (RAC) except for a small level corrosion and the degradation rate of ultimate bond strength increases with a decrease of compressive strength at $0.5 \%$ rebar corrosion. The results also demonstrate that the ultimate bond strength of reinforced RAC slightly decreases with an increase of RCA replacement. However, the relative bond strength between uncorroded rebar and RAC is little affected by RCA content, while it decreases with an increase of RCA replacement in high-strength specimens after rebar corrosion. The debonding energy between deformed rebar and RAC is found decreasing with the increment of the rebar corrosion level and increasing with an increase of RAC content.
\end{abstract}

\section{Introduction}

Modern constructions require the conservation of natural resources and the preservation of environment due to the gradual depletion of natural resources and the disposal crisis of growing wastes, for example, demolition and construction wastes. One of most common ways to mitigate these problems is to incorporate demolished wastes like recycled aggregates in new concrete for construction uses. So far, recycled aggregates have been primarily limited to lowvalue applications such as road filler materials or backfill for retaining wall in China [1]. It is recently advocated that recycled aggregates have to find their outlets in structural usages to minimize the disposal of demolished construction wastes $[1,2]$. Furthermore, RCA-containing concrete is found technically suitable for structural applications, especially if the mixture is accompanied with modifications of the mix dosage such as increase of the cementitious content [2-6].

Incorporation of recycled aggregates in structural members has to guarantee a tight bond between the rebar and the surrounding concrete so that external loadings are carried effectively. Bond behavior between RAC and the rebars has raised wide attention in the structural engineering world [713]. These previous studies focus mainly on the bond strength of RAC embedded with the deformed and plain rebars in uncorroded states; few studies were conducted on the behavior of reinforced RAC considering steel corrosion $[14,15]$. In particular, the bond behaviors between high-strength RAC and corroded rebar remain an untapped subject, although bond-slip characteristics of normal reinforced concrete under different corroded states have been extensively studied [1620]. Considering that RCA-containing concrete is innate with a higher permeability compared to normal concrete, the rebar embedded in the field-exposed reinforced RAC is prone to corrosion during its lifetime [21, 22]. It is thus necessary to examine the bond behavior of RAC under different corrosion levels.

This paper aims to test the bond behavior of reinforced RCA-containing concrete under different levels of chlorideincurred corrosion. Both low- and high-strength concrete 
TABLE 1: Physical properties of coarse aggregates.

\begin{tabular}{|c|c|c|c|c|c|}
\hline Aggregate type & Gradation & Observed density $\left(\mathrm{kg} / \mathrm{m}^{3}\right)$ & Bulk density $\left(\mathrm{kg} / \mathrm{m}^{3}\right)$ & Absorptivity (\%) & Crushed index (\%) \\
\hline Recycled & $5-31 \mathrm{~mm}$ & 2430 & 1260 & 5.96 & 19.5 \\
\hline Natural & $5-31 \mathrm{~mm}$ & 2760 & 1429 & 1.35 & 13 \\
\hline
\end{tabular}
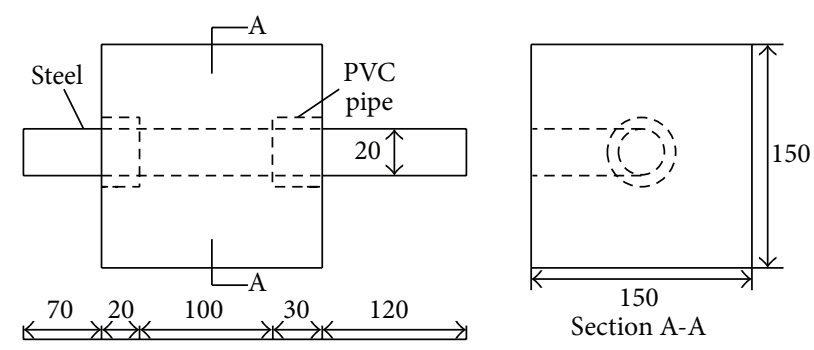

FIGURE 1: Geometry of the fabricated specimens; all units in mm.

samples were prepared with different w/c ratios. Bond-slip curves were recorded to determine the influences of RCA and corrosion levels on bond behavior.

\section{Experimental Program}

2.1. Specimens Preparations. Demolished old concrete pavement slabs in the urban area of Nanning, China, were jaw broken and then sieved for 5-31 mm coarse recycled aggregates, while natural aggregates (crushed limestone) were bought from a local commercial aggregate plant. Both aggregates were compliant with the Chinese standard GB50152-92. Basic physical properties of these aggregates were tabulated in Table 1. The normal Portland cement type 42.5 was used in this test. Medium-sized natural sand was utilized as fine aggregate in the mixture.

Two series of specimens were prepared. One was targeted as high-strength concrete with a designed water-to-cement (w/c) ratio of 0.28 (HRC), in which some amounts of the fly ash and ground granulated blast-furnace slag were added as cementitious binder. For comparison, the other was objected as low-strength concrete specimens with a designed w/c ratio of 0.50 , in order to evaluate the specimen strength on the bond behavior of corroded reinforced concrete containing RCA. For both, $0 \%, 50 \%$, and $100 \%$ of natural aggregate were replaced by the RCA, referred to hereafter as HRC1, HRC2, and HRC3 for high-strength concrete specimens, respectively, and as $\mathrm{RC} 1, \mathrm{RC} 2$, and $\mathrm{RC} 3$ for low-strength concrete samples, respectively. It should be noted that the mixture water contained $5 \%$ weight of $\mathrm{NaCl}$ in order to disseminate uniform chloride seeds in the concrete specimens. All ingredients were mixed in a concrete mixer for about $5 \mathrm{~min}$ and were then poured into $150 \mathrm{~mm}^{3}$ cubes wooden moulds (Figure 1).

The embedded rebar typed HRB335 was the quenched steel bar with a yield stress of $420 \mathrm{MPa}$ and a diameter of $20 \mathrm{~mm}$. Before being placed into the moulds, the reinforcing bars were cleaned with a $12 \%$ hydrochloric acid solution, cleaned by pure water, neutralized by calcium hydroxide solution, and finally cleaned by pure water again. Rebars were then dried for 4 hrs in a dryer cabin and were weighed with a resolution of $0.1 \mathrm{~g}$. The embedment length of the rebar was adopted as $5 d$ (Figure 1), and only its bonded zone was designed to be corroded, while both ends of the steel bar were insulated with epoxy rinse during the accelerated corrosion tests.

In total, six groups of concrete were casted with detailed mixtures tabulated in Table 2. All the demolded specimens were cured in a humid cabin with $20^{\circ} \mathrm{C}$ and $95 \%$ relative humidity for 28 days. After 28-day curing, for each sample group, 3 cubic specimens were submitted to compressive strength test while the remaining 4 reinforced RAC specimens were designed to be $0 \%, 0.5 \%, 1.5 \%$, and $2.5 \%$ rebar corrosion levels, respectively.

2.2. Corrosion Tests. Specimens prepared for corrosion tests were further immerged in $5 \% \mathrm{NaCl}$ solution for 3 days and then were corroded to the targeted corrosion level using electrochemical method. In the artificial corroded setup, parallel circuits were adopted during the corrosion process (Figure 2). Rebar corrosion level was evaluated according to Faraday's law. It was calculated according to the weight loss percentage of the corroded rebar at the bonding section.

The designed corrosion amount in terms of the mass loss of corroded rebar was estimated by [23]

$$
\eta=\frac{M I t}{2 N m e}
$$

where $\eta$ is a dimensional scale standing for the designed level of corrosion, $t(s)$; the signification of $M, I, N, m$, and $e$ is listed in Nomenclature.

The actual corrosion of a rebar may deviate somewhat from the designed one. Upon completion of pullout tests, the 
TABLE 2: Mixtures of specimen.

\begin{tabular}{|c|c|c|c|c|c|c|c|c|c|}
\hline \multirow{2}{*}{ Number } & \multirow{2}{*}{$\mathrm{w} / \mathrm{c}$} & \multicolumn{7}{|c|}{ Ingredients $\left(\mathrm{kg} / \mathrm{m}^{3}\right)$} & \multirow{2}{*}{ Slump $(\mathrm{cm})$} \\
\hline & & RA & NA & $\mathrm{C}$ & FA & $\mathrm{KF}$ & S & $\mathrm{W}$ & \\
\hline $\mathrm{HRCl}$ & 0.28 & 0 & 1050 & 420 & 90 & 90 & 670 & 168 & 21.8 \\
\hline HRC2 & 0.28 & 525 & 525 & 420 & 90 & 90 & 670 & 168 & 16.5 \\
\hline HRC3 & 0.28 & 1050 & 0 & 420 & 90 & 90 & 670 & 168 & 9.3 \\
\hline $\mathrm{RC} 1$ & 0.5 & 0 & 1150 & 420 & 0 & 0 & 750 & 210 & 12.0 \\
\hline $\mathrm{RC} 2$ & 0.5 & 575 & 575 & 420 & 0 & 0 & 750 & 210 & 4.1 \\
\hline RC3 & 0.5 & 1150 & 0 & 420 & 0 & 0 & 750 & 210 & 2.8 \\
\hline
\end{tabular}

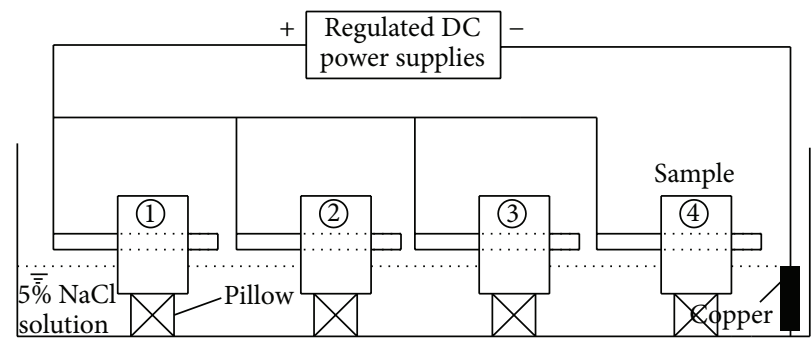

(a)

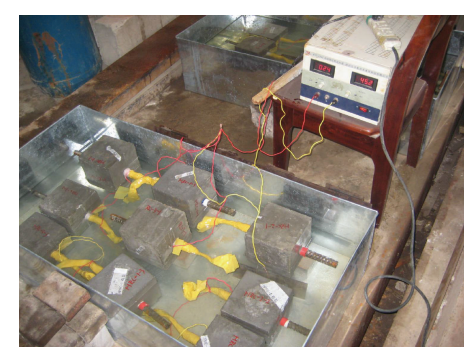

(b)

FIgURE 2: Parallel circuits used to accelerate the corrosion of the rebars.
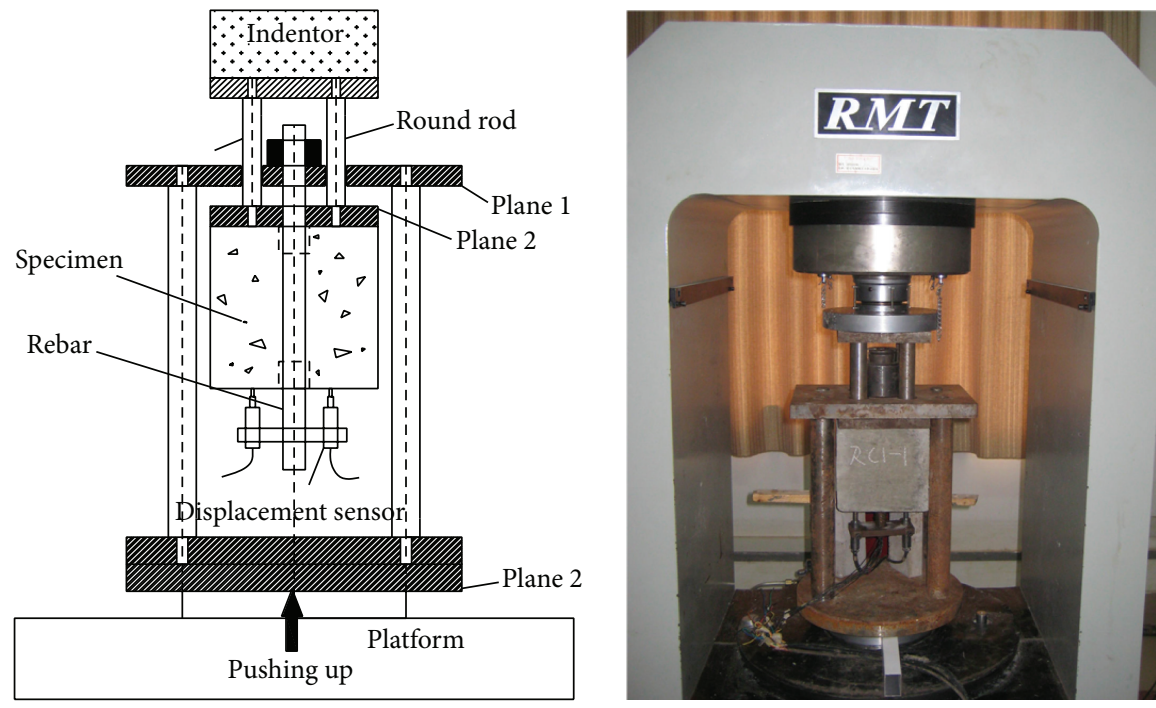

FIgURE 3: Pullout test system.

corroded rebar was dismantled from the specimen. Corrosion products were scrapped from the rebar and weighted to evaluate the actual corrosion level, which was expressed as

$$
\eta_{r}=\frac{m-m_{1}}{m}
$$

where $m_{1}(\mathrm{~kg})$ is the weight of the rebar after the corrosion products were scrapped and $m(\mathrm{~kg})$ is the weight of the rebar before the reinforcement corroded.

2.3. Load Procedures. Bond-slip behavior of the rebar was tested by use of pullout tests. Loading frames were imposed by a RMT-201 testing machine as shown in Figure 3. Load and displacement of the rebar were logged automatically by a computer. For all the tests, strains of rebars were maintained at very low level to minimize dynamical momentum occurring at the rebar-concrete interface.

The bond stress was assumed to be uniform along the anchorage length, and the average bond stress at each loading level was calculated as follows:

$$
\tau=\frac{P}{\pi d l}
$$


TABLE 3: Corrosion of different specimens.

\begin{tabular}{|c|c|c|c|c|c|}
\hline Specimen number & Current (A) & Time (h) & Crack (mm) & Measured corrosion (\%) & Designed corrosion (\%) \\
\hline HRC1-0 & - & - & 0 & 0 & 0 \\
\hline HRC1-1 & 0.03 & 35.0 & 0 & 0.57 & 0.50 \\
\hline HRC1-2 & 0.02 & 123.0 & 0.2 & 1.96 & 1.50 \\
\hline HRC1-3 & 0.02 & 256.6 & 0.65 & 2.90 & 2.50 \\
\hline HRC2-0 & - & - & 0 & 0 & 0 \\
\hline HRC2-1 & 0.04 & 26.0 & 0.1 & 0.75 & 0.50 \\
\hline HRC2-2 & 0.06 & 52.4 & 0.2 & 1.71 & 1.50 \\
\hline HRC2-3 & 0.02 & 256.6 & 0.6 & 2.54 & 2.50 \\
\hline HRC3-0 & - & - & 0 & 0 & 0 \\
\hline HRC3-1 & 0.04 & 26.0 & 0 & 0.67 & 0.50 \\
\hline HRC3-2 & 0.05 & 62.9 & 0.2 & 1.37 & 1.50 \\
\hline HRC3-3 & 0.05 & 102.6 & 0.7 & 2.7 & 2.50 \\
\hline RC1-0 & - & - & 0 & 0 & 0 \\
\hline RC1-1 & 0.09 & 12.0 & 0.25 & 0.44 & 0.50 \\
\hline RC1-2 & 0.10 & 24.4 & 0.60 & 1.42 & 1.50 \\
\hline RC1-3 & 0.13 & 38.0 & 1.35 & 2.63 & 2.50 \\
\hline RC2-0 & - & - & 0 & 0 & 0 \\
\hline RC2-2 & 0.12 & 20.3 & 0.50 & 1.70 & 1.50 \\
\hline RC2-3 & 0.12 & 41.0 & 1.30 & 2.54 & 2.50 \\
\hline RC3-0 & - & - & 0 & 0 & 0 \\
\hline RC3-1 & 0.10 & 11.0 & 0.15 & 0.73 & 0.50 \\
\hline RC3-2 & 0.12 & 20.3 & 0.60 & 2.10 & 1.50 \\
\hline RC3-3 & 0.17 & 29.0 & 1.40 & 2.90 & 2.50 \\
\hline
\end{tabular}

Note: the specimen labeled RC2-1 was broken.

where $P$ is the load reading from the RMT-201; $d$ is the diameter of the uncorroded rebar; and $l$ is the embedded length of the rebar.

\section{Test Results and Discussion}

\subsection{Test Results}

3.1.1. Corrosion Levels and Crack Width. Although corrosion of some specimens was occasionally less than the designed one due to the heterogeneousness of concrete materials, measured corrosion was in most cases greater than designed corrosion levels (Table 3). This finding was different from a previous study, which used the same corrosion-computing approach and found that measured corrosion was slightly lower than the designed one [20]. The only difference in the experimental setup was that the previous literature chose natural water as the mixture water while this study used $5 \% \mathrm{NaCl}$ solution. It is easy to understand that, for those specimens prepared with $\mathrm{NaCl}$ solution as the mixture water, the speed of rebar corrosion would be faster because enough free chloride ion can be used to transport electron charge. Table 3 demonstrates that the crack width increases with an increment of corrosion level, and greater cracking openings were observed at those specimens with lower compressive strength (HRC and RC). The reason may be that lowstrength concrete has relatively larger pore and lower tensile strength so that once the anchored rebar was corroded, corrosion products escaped preferentially from those big pores; the corrosion-induced expansive pressure introduced hoop tensile stress to the specimen. In the absence of stirrups, the specimen was susceptive to crack especially for lowstrength concrete.

3.1.2. Bond versus Slip Curves. The measured bond-slip curves of different corrosion levels and different RCA containments are shown in Figure 4, while the $G$ values in Figure 4 are the debonding energy of specimens which will be discussed in Section 3.4. Several specimens failed to test the descending branch of bond-slip curve due to steel yield and sudden break. The characteristic values of bond-slip are summarized in Table 4.

3.2. Influence of Corrosion Levels on Bond Behavior. The relationships of ultimate bond strength versus corrosion level are drawn in Figure 5. It is easy to be found in Table 4 and Figure 5 that, for the HRC1-1 specimen (high-strength RCAfree concrete under a $0.5 \%$ corrosion level), the ultimate bond strength was higher slightly than the uncorroded sample, a finding that agreed with some previous studies $[16,20$, 24-26]. This might be that minor corrosion products had generated in the interface but had not been transported sufficiently, densifying the local matrix and subsequently increasing the bond strength. Therefore, small amounts of 

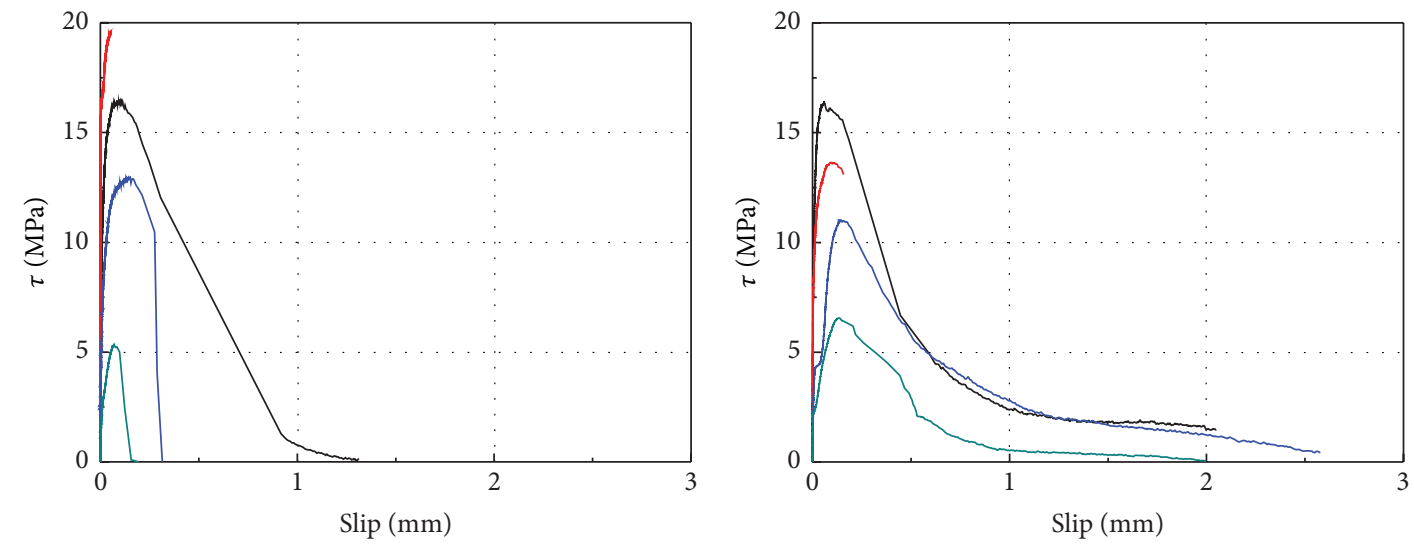

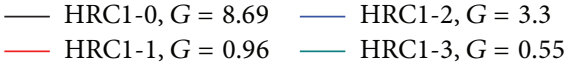

(a) HRC specimens with 0\% RCA

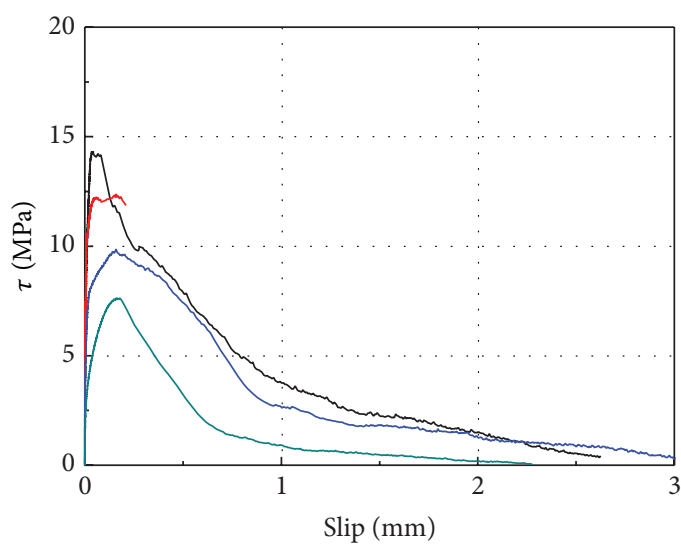

- HRC1-0, $G=11.0-$ HRC1-2, $G=9.43$

- HRC1 $1, G=2.5-$ HRC1 $-3, G=4.1$

(c) HRC specimens with $100 \%$ RCA

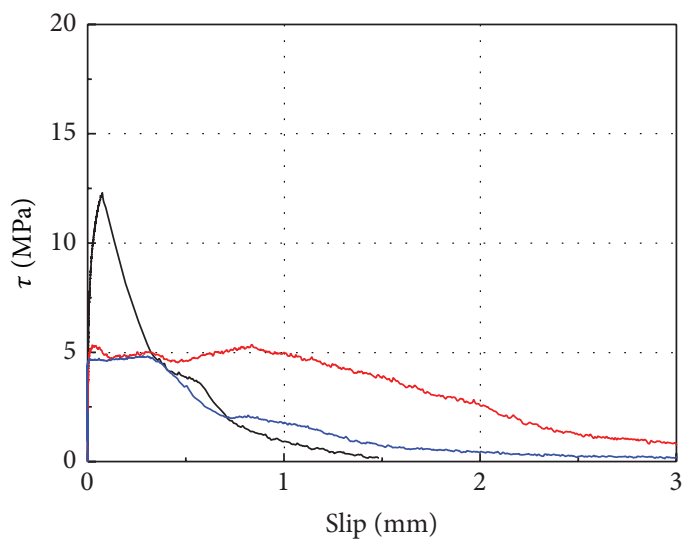

RC2-0, $G=4.85$
RC2-2, $G=10.43$$\quad$ RC2-3, $G=4.58$

(e) RC specimens with 50\% RCA

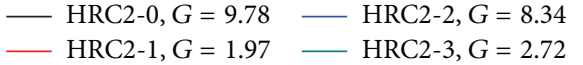

(b) HRC specimens with $50 \%$ RCA

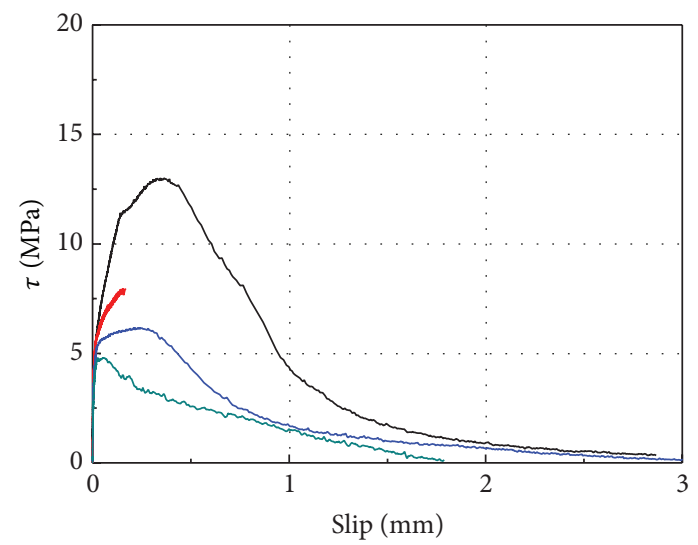

$-\mathrm{RC} 1-0, G=12.07-\mathrm{RC} 1-2, G=5.56$
$\mathrm{RC} 1-1, G=1.10 \quad \mathrm{RC} 1-3, G=3.36$

(d) RC specimens with $0 \%$ RCA

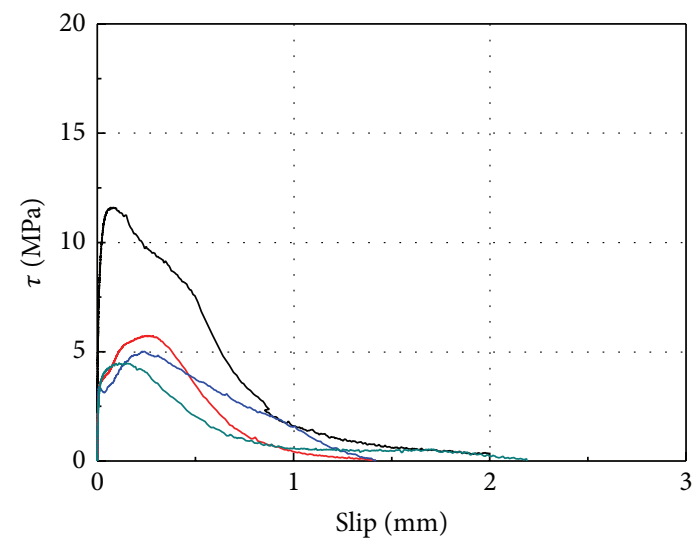

$\begin{array}{ll}\text { RC3-0, } G=7.48 & -\mathrm{RC} 3-2, G=3.80 \\ \mathrm{RC} 3-1, G=3.25 & \mathrm{RC} 3-3, G=2.84\end{array}$

(f) RC specimens with $100 \%$ RCA

FIGURE 4: Bond-slip curves of different specimens. 
TABLE 4: Bond-slip parameters of specimens under the pullout tests.

\begin{tabular}{|c|c|c|c|c|c|c|}
\hline Number & $f_{c}(\mathrm{MPa})$ & $\tau_{0}(\mathrm{MPa})$ & $\tau_{1}(\mathrm{MPa})$ & $s_{f}(\mathrm{~mm})$ & $\tau_{1} / \tau_{0}$ & Crack style \\
\hline HRC1-0 & \multirow{4}{*}{61.8} & 16.50 & 10.50 & 0.0979 & 0.64 & Splitting \\
\hline HRC1-1 & & 19.63 & - & - & - & Yield \\
\hline HRC1-2 & & 12.96 & 7.94 & 0.0944 & 0.61 & Splitting \\
\hline HRC1-3 & & 5.31 & 3.16 & 0.0696 & 0.59 & Splitting \\
\hline HRC2-0 & \multirow{4}{*}{64.9} & 16.4 & 11.41 & 0.0575 & 0.70 & \multirow{4}{*}{ Splitting } \\
\hline HRC2-1 & & 13.64 & 9.83 & 0.0913 & 0.72 & \\
\hline HRC2-2 & & 11.04 & 6.31 & 0.1448 & 0.57 & \\
\hline HRC2-3 & & 6.57 & 2.37 & 0.1345 & 0.36 & \\
\hline HRC3-0 & \multirow{4}{*}{52.6} & 14.30 & 9.49 & 0.0429 & 0.66 & \multirow{4}{*}{ Splitting } \\
\hline HRC3-1 & & 12.33 & 10.46 & 0.1525 & 0.85 & \\
\hline HRC3-2 & & 9.87 & 6.01 & 0.1575 & 0.61 & \\
\hline HRC3-3 & & 7.63 & 3.53 & 0.1600 & 0.46 & \\
\hline RC1-0 & \multirow{4}{*}{39.7} & 13.01 & 9.75 & 0.3451 & 0.75 & \multirow{4}{*}{ Splitting } \\
\hline RC1-1 & & 7.98 & 5.59 & 0.1540 & 0.7 & \\
\hline RC1-2 & & 6.19 & 4.39 & 0.2397 & 0.71 & \\
\hline RC1-3 & & 4.80 & 2.83 & 0.0535 & 0.59 & \\
\hline RC2-0 & \multirow{3}{*}{40.6} & 12.31 & 7.93 & 0.0743 & 0.64 & \multirow{3}{*}{ Splitting } \\
\hline RC2-2 & & 5.31 & 2.13 & 0.0406 & 0.4 & \\
\hline $\mathrm{RC} 2-3$ & & 4.79 & 2.35 & 0.0144 & 0.49 & \\
\hline RC3-0 & \multirow{4}{*}{32.0} & 11.61 & 7.98 & 0.0677 & 0.69 & \multirow{4}{*}{ Splitting } \\
\hline RC3-1 & & 5.75 & 3.90 & 0.2528 & 0.68 & \\
\hline RC3-2 & & 5.02 & 2.95 & 0.2272 & 0.59 & \\
\hline RC3-3 & & 4.49 & 2.14 & 0.1107 & 0.47 & \\
\hline
\end{tabular}

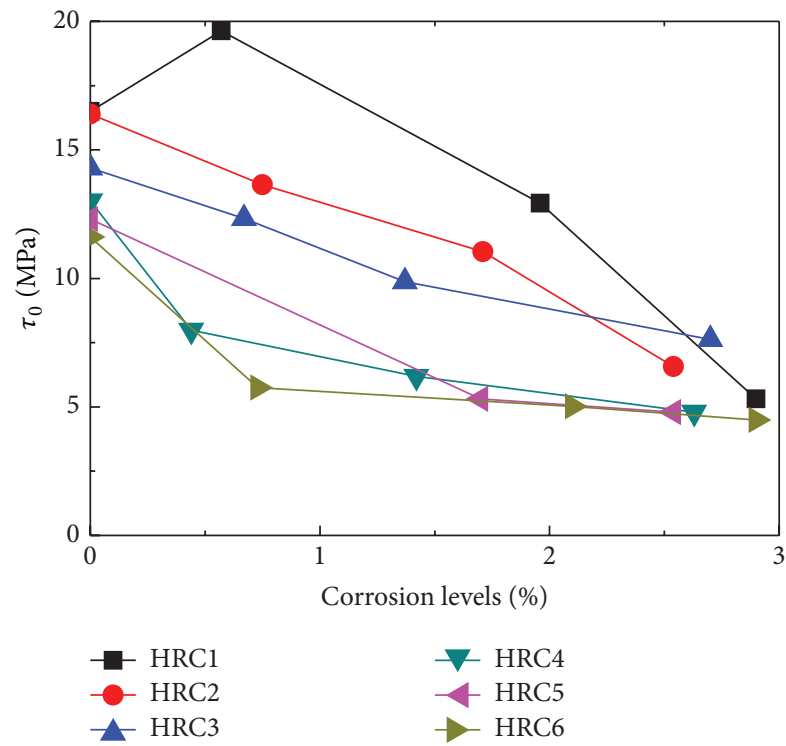

FIGURE 5: $\tau_{0}$ versus corrosion level.

corrosion were beneficial to the bond performance of steel reinforcing bars.

Except for HRC1-1 specimen, similar to reinforced normal aggregate concrete, it can be observed that the ultimate bond strength of RAC decreases with an increase of corrosion level (Figure 5). Furthermore, the degradation rate of bond strength is greater in RC series than in HRC series when corrosion rate is $0.5 \%$, while a contrary result is observed as the corrosion rate increased to $1.5 \%$ and $2.5 \%$. This result illustrates that bond degradation rate increases with a decrease of compressive strength at a relative minor corrosion (such as $0.5 \%$ corrosion rate in all the specimens except for HRC1) but decreases until corrosion increases towards a certain level. To analyze the antisliding ability of reinforced RAC, we define $K$ as $\tau_{1} / \tau_{0}$ and plot $K$ versus corrosion rate in Figure 6. All series of RAC in Figure 6 show a descending tendency of $K$ value with an increase of corrosion level, which demonstrates that increasing corrosion rate gradually weakens the antisliding ability of reinforced RAC. The main reason is that corrosion-induced cracks reduce the mechanical interlock between corroded rebars and RAC, and it finally makes rebar more likely to slip from RAC.

3.3. Influence of RCA on Bond Behavior. The ultimate bond strength decreased with an increase of RCA containment before and after rebar corrosion (Figure 7(a)), as expected. The ultimate bond strength comprises adhesive force, mechanical interlock, and friction between the rebar and the surrounding concrete. The adhesive force and mechanical interlock decreased with an increase of the RCA replacement ratio because of the innate microcrack of the RCA. When the RCA replacement level increased from $0 \%$ to $100 \%$, ultimate bond strengths of uncorroded specimens declined from 16.4 $\mathrm{MPa}$ to $14.3 \mathrm{MPa}$ for high-strength specimens 
TABLE 5: $G$ values of uncorroded specimens with different RCA content (unit: MPa.mm).

\begin{tabular}{lcccc}
\hline Specimens & Rebar type & 0\% RCA & 50\% RCA & 100\% RCA \\
\hline HRC in this study & Deformed & 8.7 & 9.8 & 4.8 \\
RC in this study & Deformed & 12.0 & 71.7 & 7.5 \\
Xiao and Falkner, 2007 [7] & Deformed & 36.9 & 30.3 & 76.0 \\
\hline
\end{tabular}

Note: integral of the debonding energy from Xiao and Falkner work was evaluated from the reported load-slip spectrums; some minor errors may happen during the data reproducing process.

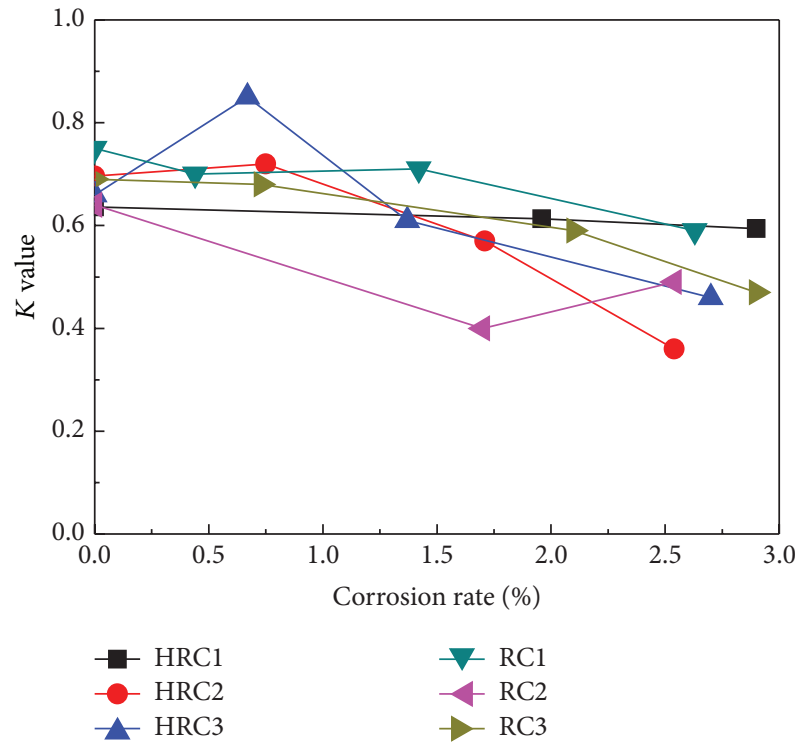

FIgURE 6: $K$ versus corrosion level.

and from 13.0 MPa to $11.6 \mathrm{MPa}$ for low-strength samples. The reductions were relatively small, roughly agreeing with findings in previous studies $[7,8,11]$. As the compressive strength of RCA-containing plain concrete declined with the increase of the RCA levels, it was reasonable that the RCAcontaining concrete compromised some levels of the ultimate bond strength.

Because the compressive strength of concrete with different RCA ratio is not uniform for a specific w/c ratio, it seems reasonable to compare the relative bond strength of RAC to analyze the influence of RCA replacement on ultimate bond strength. The relative bond strength is defined as follows [27]:

$$
\tau_{r}=\frac{\tau_{0}}{\sqrt{f_{c}}}
$$

The relationship between $\tau_{r}$ and RCA replacement is shown in Figure $7(\mathrm{~b}) \cdot \tau_{r}$ remained nearly unchanged with an increase of RAC replacement before rebar corrosion (HRC, $\eta=0 \%$, and RC, $\eta=0 \%$, in Figure $7(\mathrm{~b})$ ), a correlation inferring the minimal effect of RCA level on relative bond strength. However, once the steel is corroded, $\tau_{r}$ declines with an increase of RAC replacement in high-strength specimens except for $\eta=2.5 \%$ but still has a negligible fluctuation as the increase of RAC replacement in low-strength specimens. This result illustrates that RCA replacement is more sensitive to reducing the bond strength for high-strength RAC after rebar corrosion, but less sensitive for low-strength RAC. A probable reason is that a greater brittleness is performed in highstrength RAC than low-strength RAC. Once the corrosioninduced crack occurred, the mechanical interlock accounted for major proportion of bond strength losses faster in highstrength RAC, even though the maximum crack width in high-strength RAC is less with the same corrosion level.

3.4. Debonding Energy of Specimens. Although the bond behavior between uncorroded rebar and RAC is wildly researched in previous studies, the debonding energy is seldom considered as a surrogate of the bond performance of reinforced RAC [7-15]. G(MPa-mm) values in Figure 4 which represent the debonding energy of specimens are calculated as follows:

$$
G=\int_{0}^{\infty} \tau(s) d s
$$

Due to the increase of the corrosion level that discounted the ultimate bond strength, the $G$ values thus declined with corrosion levels as well (shown in Figure 4), which demonstrated that debonding a corroded rebar required a lower energy than pulling out an uncorroded rebar did.

Though incorporating RCA in reinforced concrete sacrificed the ultimate bond strength somewhat, energies required to debond rebars fully from RCA-containing concrete increased with RCA replacement, as indicated on the $G$ values (comparison of Figures 4(a), 4(b), and 4(c)). This is because the descending branch of the RCA-containing concrete decreases in a relatively softer manner compared to RCAfree concrete. This indicates that the frictions between rebar and surrounding concrete increase with RCA contents. One possible reason may be that, after overcoming the adhesion, the residual mortar originally attached in the RCA is detached and resided at the concrete-rebar interface, increasing the interfacial friction and subsequently the debonding energy. Similar findings had been reported by Xiao and Falkner [7]. Table 5 compares the $G$ values in Xiao and Falkner work with those in this study; the result for RC series can be deemed to be the dispersion of test data, while debonding energies in Xiao and Falkner work were larger than those in this study, possibly because the embedded length, rebar diameter, and the concrete mixture are different in two experiments.

The interpretation mentioned above seems plausible because Xiao and Falkner work demonstrated that the debonding energy decreased with the increase of RCA contents when the plain rebar was embedded (Row 5 in Table 5) 


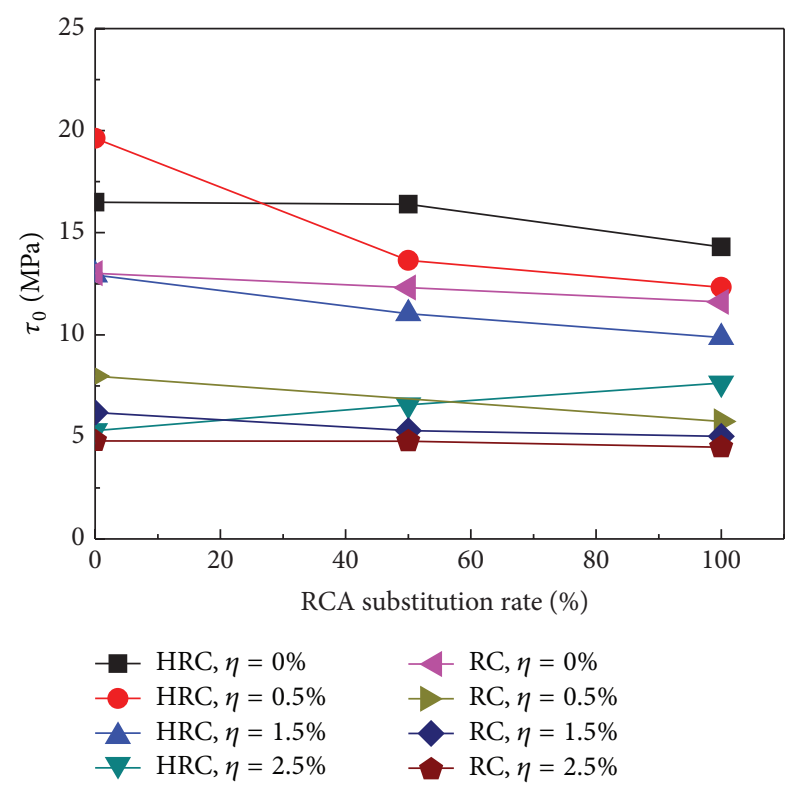

(a) Ultimate bond strength

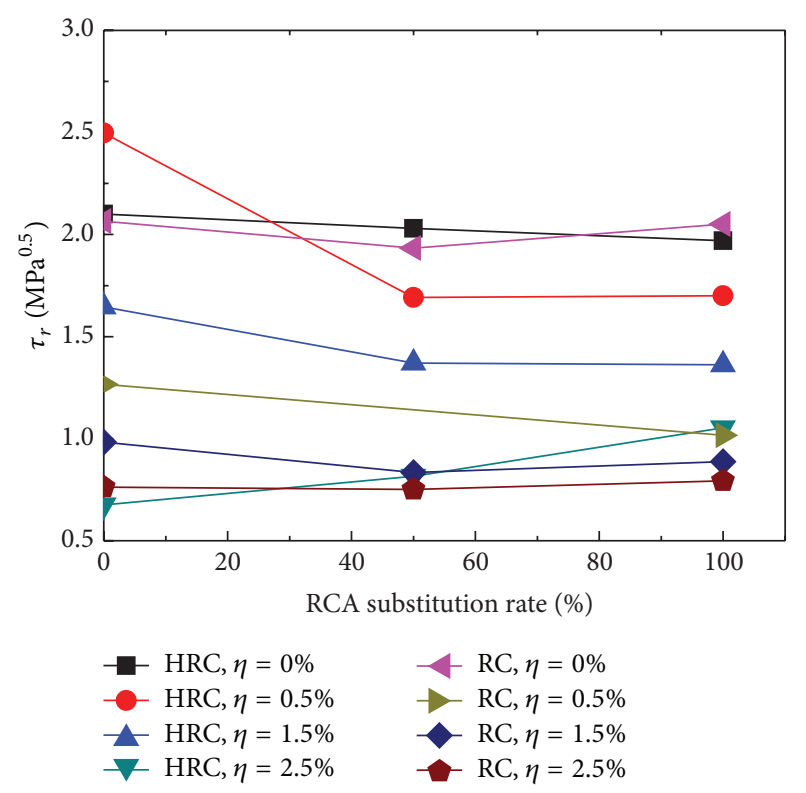

(b) Relative bond strength

FIgURE 7: Bond strength versus RCA replacement.

but a contrary trend was observed when the deformed rebar was anchored (Row 4 in Table 5). This interpretation also held true in the case that the embedded rebar was corroded. Although some corrosion products oozed to the pore of the RCA residual mortar and densified the bonding interface, there was no evidence that the corrosion fastened or loosed the attached residual mortar on the RCA surface. The detached debris was thus expected to increase with the RCA contents after the bonding adhesion was overcome.

\section{Summary and Conclusions}

The experimental conditions herein may be somewhat different from those conditions in other studies. The mix proportion and raw materials may be different and will affect the results. As our study represents typical experimental parameters for the correction of reinforcing concrete with different level of RCA, the authors believe any variations of the concrete mixture, pullout tests procedure, and others will challenge the reproduction of the experiment and will not cause substantially different or reverse conclusions.

(1) High-strength RAC tends to crack in a smaller scale due to its relatively higher tensile strength. Corrosion products at the low-strength RAC may ooze preferentially through those big-scale pores and cause larger surface cracking width at the concrete surface.

(2) A small level corrosion in the reinforced RAC first increases the ultimate bond strength of the rebar, and then, with the increment of rebar corrosion, the ultimate bond strength decreases, while the degradation rate increases with a decrease of compressive strength at a $0.5 \%$ rebar corrosion but decreases until corrosion level increases towards $1.5 \%$ and $2.5 \%$. Additionally, increasing corrosion rate gradually weakens the antisliding ability of reinforced RAC.

(3) The ultimate bond strength of reinforced RAC slightly decreases with an increase of RCA replacement. However, the relative bond strength between uncorroded rebar and RAC is little affected by RCA containment, while it decreases with an increase of RCA replacement in high-strength specimens after rebar corrosion.

(4) The debonding energy is found decreasing with an increase of the rebar corrosion level and increasing with an increase of RCA content; however, this type of increase vanishes when a RCA-containing concrete embedded with plain rebars.

\section{Nomenclature}

$\eta, \eta_{r}: \quad$ Designed and measured corrosion level of rebar, respectively

M: $\quad$ Molar mass of rebar, $56 \mathrm{~g} / \mathrm{mol}$

I: $\quad$ Average current

$N$ : Avogadro constant, $6.02 \times 10^{23} \mathrm{~mol}^{-1}$

$e$ : $\quad$ Electron charge, $1.6 \times 10^{-19} \mathrm{C}$

$m, m_{1}$ : Weight of rebar before and after corrosion, respectively

$\tau, P: \quad$ Bond stress and applied load

$G$ : Debonding energy

$d, l$ : Diameter and embedded length of uncorroded rebar

$\tau_{0}, s_{f}$ : Peak bond stress and corresponding slip

$f_{c}: \quad$ Cubic compressive strength of concrete 
$\tau_{1}$ : Bond stress corresponding to first slip occurring

$K: \tau_{1} / \tau_{0}$

$\tau_{r}$ : Relative bond strength $\left(\tau / \sqrt{f_{c}}\right)$.

\section{Conflict of Interests}

The authors declare that there is no conflict of interests regarding the publication of this paper.

\section{Acknowledgments}

The authors would like to appreciate the funding from Natural Science Foundation of China (no. 51308135) and the Program of Guangxi Natural Science Foundation (no. 2014GXNSFBA118242).

\section{References}

[1] X. Li, "Recycling and reuse of waste concrete in China. Part I. Material behaviour of recycled aggregate concrete," Resources, Conservation and Recycling, vol. 53, no. 1-2, pp. 36-44, 2008.

[2] M. Etxeberria, A. R. Marí, and E. Vázquez, "Recycled aggregate concrete as structural material," Materials and Structures, vol. 40, no. 5, pp. 529-541, 2007.

[3] I. S. Ignjatović, S. B. Marinković, Z. M. Mišković, and A. R. Savić, "Flexural behavior of reinforced recycled aggregate concrete beams under short-term loading," Materials and Structures/Materiaux et Constructions, vol. 46, no. 6, pp. 1045-1059, 2013.

[4] A. B. Ajdukiewicz and A. T. Kliszczewicz, "Comparative tests of beams and columns made of recycled aggregate concrete and natural aggregate concrete," Journal of Advanced Concrete Technology, vol. 5, no. 2, pp. 259-273, 2007.

[5] G. Fathifazl, A. G. Razaqpur, O. B. Isgor, A. Abbas, B. Fournier, and S. Foo, "Shear capacity evaluation of steel reinforced recycled concrete (RRC) beams," Engineering Structures, vol. 33, no. 3, pp. 1025-1033, 2011.

[6] V. Corinaldesi and G. Moriconi, "Influence of mineral additions on the performance of $100 \%$ recycled aggregate concrete," Construction and Building Materials, vol. 23, no. 8, pp. 2869-2876, 2009.

[7] J. Xiao and H. Falkner, "Bond behaviour between recycled aggregate concrete and steel rebars," Construction and Building Materials, vol. 21, no. 2, pp. 395-401, 2007.

[8] L. Butler, J. S. West, and S. L. Tighe, "The effect of recycled concrete aggregate properties on the bond strength between RCA concrete and steel reinforcement," Cement and Concrete Research, vol. 41, no. 10, pp. 1037-1049, 2011.

[9] G. Fathifazl, A. Ghani Razaqpur, O. Burkan Isgor, A. Abbas, B. Fournier, and S. Foo, "Bond performance of deformed steel bars in concrete produced with coarse recycled concrete aggregate," Canadian Journal of Civil Engineering, vol. 39, no. 2, pp. 128-139, 2012.

[10] M. Guerra, F. Ceia, J. de Brito, and E. Júlio, "Anchorage of steel rebars to recycled aggregates concrete," Construction and Building Materials, vol. 72, pp. 113-123, 2014.

[11] S.-W. Kim and H.-D. Yun, "Influence of recycled coarse aggregates on the bond behavior of deformed bars in concrete," Engineering Structures, vol. 48, pp. 133-143, 2013.
[12] M. J. R. Prince and B. Singh, "Bond behaviour between recycled aggregate concrete and deformed steel bars," Materials and Structures, vol. 47, no. 3, pp. 503-516, 2013.

[13] S. Seara-Paz, B. González-Fonteboa, J. Eiras-López, and M. F. Herrador, "Bond behavior between steel reinforcement and recycled concrete," Materials and Structures, vol. 47, no. 1-2, pp. 323-334, 2014.

[14] Y. Zhao, H. Lin, K. Wu, and W. Jin, "Bond behaviour of nor$\mathrm{mal} /$ recycled concrete and corroded steel bars," Construction and Building Materials, vol. 48, pp. 348-359, 2013.

[15] J. Xiao and B. Lei, "Experimental study on bond behavior between corroded steel bars and recycled concrete," Journal of Building Structures, vol. 32, no. 1, pp. 58-62, 2011.

[16] G. J. Al-Sulaimani, M. Kaleemullah, and I. A. Basunbul, "Influence of corrosion and cracking on bond behavior and strength of reinforced concrete members," ACI Structural Journal, vol. 87, no. 2, pp. 220-231, 1990.

[17] L. Amleh and S. Mirza, "Corrosion influence on bond between steel and concrete," ACI Structural Journal, vol. 96, no. 3, pp. 415-423, 1999.

[18] Y. Auyeung, P. Balaguru, and L. Chung, "Bond behavior of corroded reinforcement bars," ACI Structural Journal, vol. 97, no. 2, pp. 214-220, 2000.

[19] K. Bhargava, A. K. Ghosh, Y. Mori, and S. Ramanujam, "Corrosion-induced bond strength degradation in reinforced concrete-Analytical and empirical models," Nuclear Engineering and Design, vol. 237, no. 11, pp. 1140-1157, 2007.

[20] C. Fang, K. Lundgren, L. Chen, and C. Zhu, "Corrosion influence on bond in reinforced concrete," Cement and Concrete Research, vol. 34, no. 11, pp. 2159-2167, 2004.

[21] J. P. Hwang, H. B. Shim, S. Lim, and K. Y. Ann, "Enhancing the durability properties of concrete containing recycled aggregate by the use of pozzolanic materials," KSCE Journal of Civil Engineering, vol. 17, no. 1, pp. 155-163, 2013.

[22] K. Y. Ann, H. Y. Moon, Y. B. Kim, and J. Ryou, "Durability of recycled aggregate concrete using pozzolanic materials," Waste Management, vol. 28, no. 6, pp. 993-999, 2008.

[23] G. Mancini and F. Tondolo, "Effect of bond degradation due to corrosion-a literature survey," Structural Concrete, vol. 15, no. 3, pp. 408-418, 2014.

[24] J. G. Cabrera, "Deterioration of concrete due to reinforcement steel corrosion," Cement and Concrete Composites, vol. 18, no. 1, pp. 47-59, 1996.

[25] H.-S. Lee, T. Noguchi, and F. Tomosawa, "Evaluation of the bond properties between concrete and reinforcement as a function of the degree of reinforcement corrosion," Cement and Concrete Research, vol. 32, no. 8, pp. 1313-1318, 2002.

[26] A. A. Almusallam, A. S. Al-Gahtani, and A. R. Aziz, "Effect of reinforcement corrosion on bond strength," Construction and Building Materials, vol. 10, no. 2, pp. 123-129, 1996.

[27] P. Soroushian, K.-B. Choi, G.-H. Park, and F. Aslani, "Bond of deformed bars to concrete: effects of confinement and strength of concrete," ACI Materials Journal, vol. 88, no. 3, pp. 227-232, 1991. 

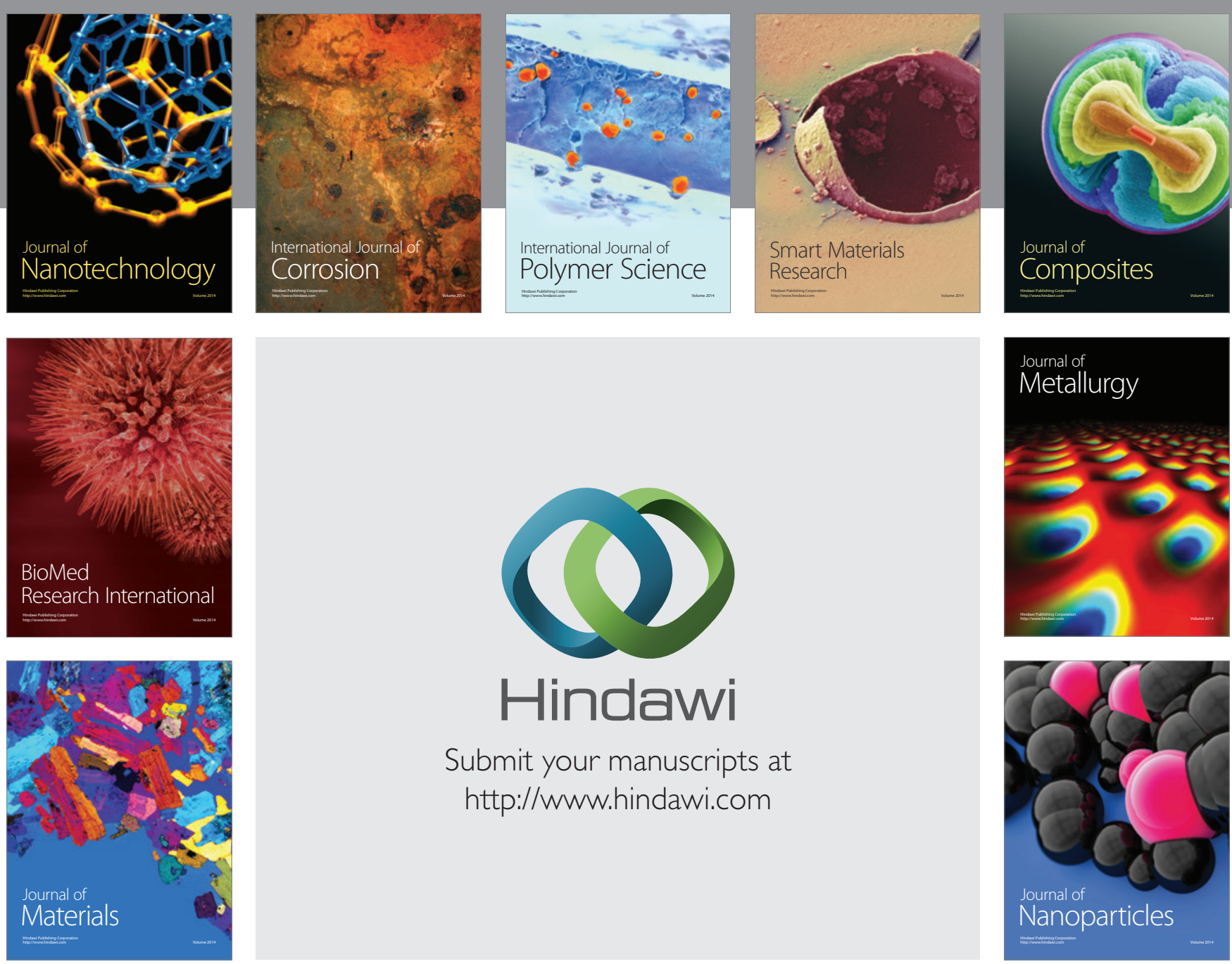

Submit your manuscripts at http://www.hindawi.com
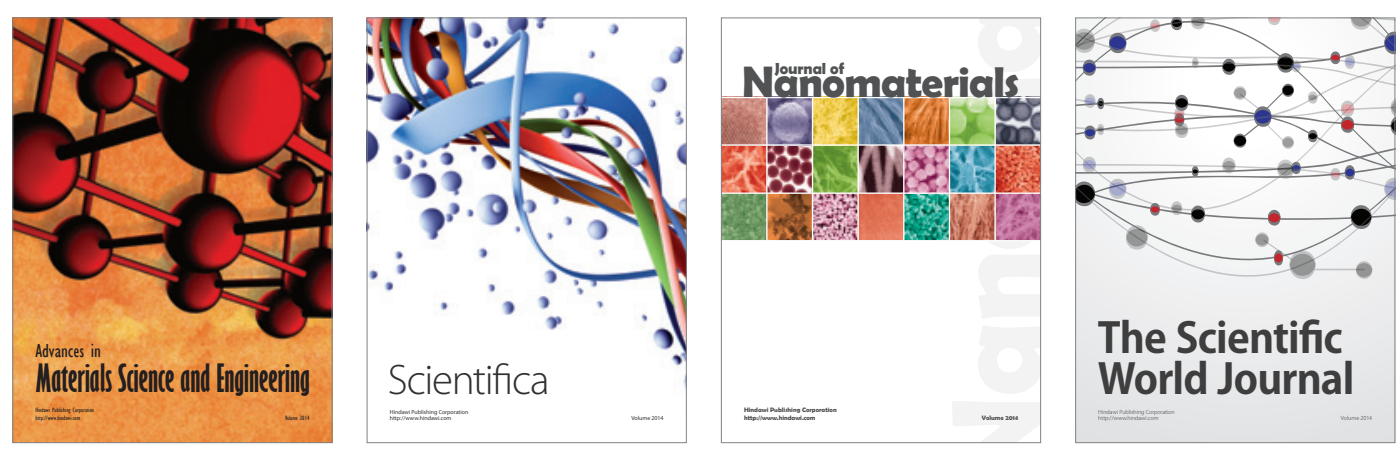

\section{The Scientific World Journal}
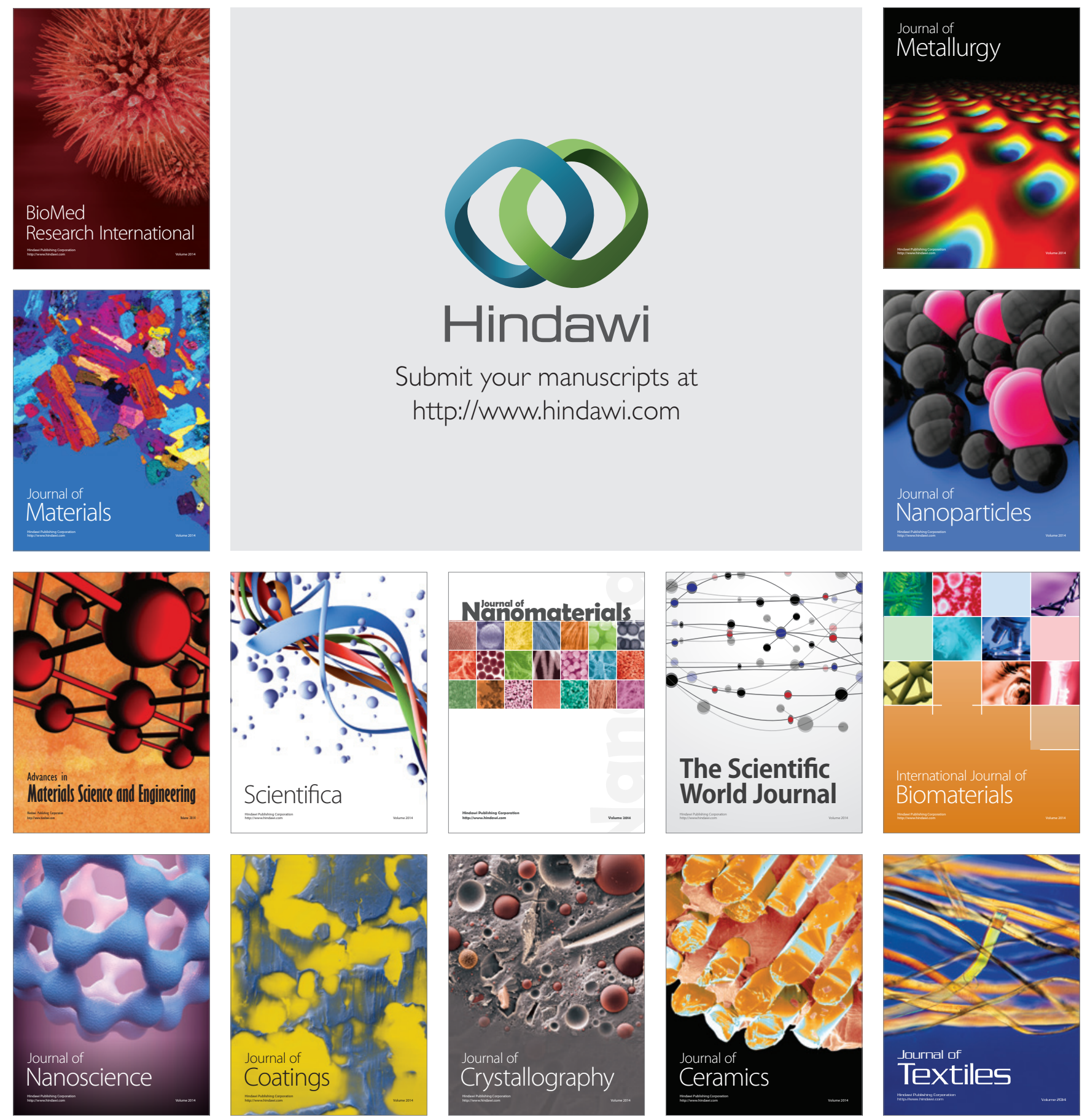